\title{
Correction to: Bio-inert Interactions in an Oil-Microorganisms System
}

Lidia I. Svarovskaya, Andrey Y. Manakov, Lyubov K. Altunina and Larisa A. Strelets

\section{Correction to:}

Chapter 11 in: O. V. Frank-Kamenetskaya et al. (eds.), Processes and Phenomena on the Boundary Between

Biogenic and Abiogenic Nature, Lecture Notes

\section{in Earth System Sciences,}

https://doi.org/10.1007/978-3-030-21614-6_11

In the original version of the book, the co-author's name "Andrey S. Stoporev" was inadvertently included in the title page of the chapter. This has now been removed. The chapter and book have been updated with the changes. 